\title{
BARRIERS TO THE DEVELOPMENT OF SME'S IN THE AUSTRALIAN CONSTRUCTION INDUSTRY
}

\author{
Anthony Mills and J im Smith, University of Melbourne \\ Associate Professor Peter Love, Edith Cowan University
}

\begin{abstract}
INTRODUCTION
The aim of this research is to identify the barriers to the development of small to medium enterprises (SME's) in the Australian construction industry, including means for reducing and overcoming them. Preliminary research (Mills et al., 2002) shows that SME's in non-metropolitan areas often find it difficult to compete effectively with metropolitan-based organisations for projects in regional Victoria. This has resulted in a depletion of regional jobs and skills leading to reduced business activity and investment in regional areas.
\end{abstract}

In addition, research undertaken by Smith et al. (2000) has found that non-metropolitan based building contractors (in particular) face difficulties in being considered, or preselected, for medium to large sized government and private sector projects in regional areas of Victoria. Even when included on selected lists of tenderers for projects in their region, many were unable to compete against their metropolitan-based rivals.

This research compares the operational characteristics of construction firms in both metopolitan and regional areas. The information is used to examine the effect of the market on the operation of SME's in construction in order to identify barriers to their development.

The conclusion of this research suggests that a range of initiatives are needed to raise the performance and capabilities of SME's in regional areas, so that they are as adept as metropolitan counterparts in winning tenders in their own regions; it also identifies some potential policy initiatives. This research was supported by the University of Melbourne and the Building Commission of Victoria.

\section{BACKGROUND}

Many non-metropolitan areas are facing economic and social problems due to a decline in population, and withdrawal of many services. Many regional areas are looking for an economic and social response to support and maintain their existing community fabric. The alternative is long-term decline and de-population. Many observers including Disney (1993) and Steinke (1977) agree that this decline should be arrested and the needs of these communities should be given closer attention.

One response to supporting regions is to provide facilities and infrastructure to allow these communities to enjoy the same range of services as those in metropolitan areas. This often means the construction of new facilities or renovation of buildings. The additional employment activity (albeit temporary) these projects inject into an area can provide an economic boost to firms and businesses in the locality. The boost in investment that building provides is a longerterm expression of self-reliance and confidence. Thus, this research suggests that construction in regional areas does have a significant role to play in underpinning the social and economic life of regional communities.

The construction industry is a relatively large employer of labour, either directly as employees, suppliers and subcontractors, or indirectly, in the large number of small businesses that make up the sector. Many of these small businesses are found in regional areas, forming a significant part of business activity, and for these reasons governments take an active interest in the health of the construction industry.

The Australian government has also recognised new economic research that highlights the importance of innovation to industrial sectors and the overall national economy. It is particularly aware that strategies to be developed should enmesh the (construction) industry into what the OECD calls the Learning Economy. one that is knowledge intensive, innovative, flexible and adaptive and characterised by the fast and effective diffusion of information, characteristics which, in the past, have not been 
evident in the building and construction industry (DISR, 1999, p. 36).

Regional construction companies have much to gain from linking into expanded networks of IT, tender information, supply chains, education, training and $\mathrm{e}$ commerce. Such an approach could mitigate the effects of the "tyranny of distance" felt most keenly by regional Australia. Regional building companies along with other regional industry must be given the opportunity to participate in the stated fourpronged national strategy specified in the Action Agenda (DISR, 1999) including;

- increase awareness of the benefits of IT

- support the development of industry standards and shared databases

- encourage and focus on added value from the use of IT

- support restructuring of the industry supply chain to leverage benefits from IT.

This research gives a regional focus to these defined national objectives by developing practical and workable strategies for their implementation using an IT strategy that may enable regional SME's to acquire skills and play their full part in the local, state and national economy.

Linking regional areas and contractors into the more economically active metropolitan areas by the use of information technology is obvious, but to date has not been used to overcome disadvantage. Such a development opens up a whole range of policy, training and project opportunities for regional contractors to participate in more easily than they could in the past.

The main objectives of this research are to:

1. identify the range of problems encountered by regional and metropolitan firms tendering for state and local government building projects in regional areas

2. determine the significance of these problems to the various stakeholders in regional areas

3. design and develop an e-commerce strategy to improve the capabilities of regional construction contractors so they can compete or work effectively with their metropolitan-based rivals as independent regional contractors.
This research is primarily concerned with developing a framework for identifying the critical factors that militate against regional contractors succeeding in winning tenders in their own regional areas of Victoria.

\section{Economic Markets For Construction}

The important aspects of the structure of the Australian building and construction industry are well documented in the five yearly surveys undertaken by the Australian Bureau of Statistics (ABS, 1999). There were some 194,000 firms in the industry in 199697 , this figure covers several non-competing sectors of the industry such as, residential building $(31,000)$, non-residential building $(2,100)$, non-building construction $(3,100)$ and special trades $(158,000)$. In addition, $93.8 \%$ of firms have four or less employees, $5.7 \%$ have from five to thirteen employees, and the remaining $0.5 \%$ have more than 13 employees.

Research by Runeson (2000) confirms that a very large number of small firms operate in the construction industry. Runeson further demonstrates that other measures can be used to show that the construction industry has a very low concentration ratio (i.e., a few firms dominate the industry) and that profit levels are generally poor (less than $4 \%$ of turnover), indicating that the industry is governed by the rules of "perfect competition".

Perfect competition is defined as a market where the action of individual firms has no effect on the market price for goods or services (Runeson, 2000). Thus, according to the author "there is also a strong feeling that the individual builder has no influence over prices and output. Certainly, the participants feel that way due to the absence of any real market power." (Runeson, 2000, p 170).

The construction industry is highly competitive, and it seems improbable that any one firm is able to control the behaviour of the market. This leads to the conclusion that the market conditions are outside the control of firms, consequently there is likely to be a narrow range of projects for which any individual firm is going to be effectively competitive.

\section{The Effect of Contract Size and Type}

Research by Drew and Skitmore (1997) supports the work by Runeson. They comment that "the construction industry is highly fragmented with the dominant firm being 
the small contractor. Low entry and exit barriers characterise construction markets, especially for small firms."

The conclusion of Drew and Skitmore's research was that the most competitive contractors appear to be those with a preferred contract value range, and they suggest that this approach in future may be used by contractors as a basis for assessing bid performance This indicates that the best clustering of contractors may be based on typical project size ranges; the effect of project type may also be significant. This indicates that contractors may have preferences towards certain projects and values, to which they have become accustomed (Drew and Skitmore, 1997, p 470).

In research by Briscoe (1988) the character of contracting markets is set by the type and nature of the work, the geographical location and the nature of the client - the exact type of competition experienced by the contracting firm depends on all these factors.

Other research suggests that the industry is best described as project-based with vertical integration defining the segmentation of contractors (Langford and Male, 1991). They consider construction in terms of geographically dispersed project-based vertical markets that operate world wide from local to international arenas.

The results of the above past research suggest that costruction competitivness is best obtained when firms specialise in small sub-markets; this is generally accepted to mean particular geographical areas, project types and value ranges. Conversly, firms are likely to become less competitive if they attempt to cover too many sub-markets. Firms that are not is a position to specialise, due to the natuure of their market, are likely to become less competitive over time.

\section{Regional Construction Markets}

The study by Smith et al. (2000) looked at the demand and supply factors that influence regional construction markets. The aim was to establish whether an effective market exists, and whether there are barriers to the participation of firms in that market. The report provides insights into the nature of regional tendering markets in the southwest region of Victoria.
According to Smith et al. there is considerable uncertainty about the health of nonmetropolitan construction markets. Regional construction firms operate from nonmetropolitan centres in what has been presumed to be a homogeneous subset of the national construction market. However, the reality is more complex, as many regional construction firms are small and face many difficulties not experienced by metropolitanbased contractors.

Smith et al. identified that non-metropolitan based building contractors faced difficulties in being considered, or prequalified, for medium to large sized projects in their own regional areas of Victoria. They reported that even when included on lists of prequalified tenderers for projects in their region, the locally based contractors face serious problems of winning tenders against their metropolitan-based rivals. Problems identified included:

- Excessive competition from metropolitan based firms

- Cost disadvantage due to distance

- Little vertical integration.

These projects include government and non-government projects such as schools, libraries, hospitals, police stations, industrial plants, civic buildings and the like. The report speculated as to whether any government regional initiatives could be pursued to redress the balance. Alternatively, changes in market dimensions may mean that regional construction markets are no longer viable.

This research suggests that the role of construction in the regional or nonmetropolitan areas of Australia does have a significant role to play in underpinning the social and economic life of regional communities. The specific objective of the research is to identify the barriers encountered by firms tendering for building projects in non-metropolitan areas throughout Australia. This is achieved by comparing the operational characteristics of construction firms from both metopolitan and non-metropolitan areas. The aim is to provide a detailed picture of regional tendering markets by identifying the problems or factors that may inhibit competitive bidding in regional areas. 


\section{RESEARCHQUESTIONS AND METHODOLOGY}

As previously mentioned preliminary research undertaken by the authors (Smith et al. 2000) for the State Government of Victoria identified that non-metropolitan based building contractors face difficulties in being considered for medium to large sized projects in non-metropolitan areas of Victoria. Therefore a survey was developed which was designed to explore the following research question:

What operational factors impact on the ability of regional contractors to bid competitively against metropolitan-based contractors?

These operational factors are considered under the headings of finance, labour, staff development, market, travel, and information technology. This research presents a analysis of a survey of the operational characteristics of both regional and metropolitan contractors in Victoria, Australia. The questionnaire comprised 38 factors that were perceived to impact on the ability of construction firms to effectively operate their businesses. Each respondent was asked to indicate the significances of each of the factors on a Likert scale from one (low impact) to five (high impact). The mean scores were calculated and presented in the results below.

A database of 550 contractors was compiled from various sources, including the Victorian Building Commission, Department of Infrastructure pre-qualification lists and the Yellow Pages. A balance of numbers between regional and metropolitan contractors was attempted and the final locations of contractors based on postcodes indicated $46.2 \%$ were regional and $53.8 \%$ were metropolitan contractors.

After removing the 'return to sender' firms (52) from the total (550) left 498 delivered surveys. Out of this total, 172 survey returns were made giving a response rate of $34.5 \%$. In construction research this is a good return rate (Chan and Fung, 1996). Within the 172 surveys received, $56.4 \%$ were from metropolitan Melbourne firms, compared with $43.6 \%$ from regional Victoria.
In terms of the analysis of the survey data it was necessary to identify the comparative difficulties encountered by regional and metropolitan contractors of a similar size. This characteristic was considered to provide the most reliable basis for a valid comparison. Average Company Turnover emerged as the best variable to group companies by size. Figure 1 indicates the profile of the respondent companies in the two groups. Companies with a turnover of between $A \$ 1.1$ and $A \$ 5.0$ million were close to the mean and most frequent in both groups and thus chosen as the comparison group. '

For these reasons this attribute was chosen to compare the two groups and all the 73 contractors in this category were selected for analysis. From this total of 73 contractors, $43(58.9 \%)$ were based in Melbourne and $30(41.1 \%)$ were from regional areas. The authors consider this is a large enough sample to validate a comparison between the groups and all the data analysis is based upon these 73 respondents.

\section{RESULTS ANDDISCUSSIONS}

Overall results compare the Likert scores between regional and metropolitan contractors for the characteristics measured in the survey as summarised below: size of firms, financial operational difficulties, labour difficulties, staff development/learning, market difficulties, distances travelled to site, and information technology. The significant comparisons are now presented for information and discussion.

\section{Size of Firms}

Metro-based contractors of this size employ slightly more directly employed people with an average of 7.58 as against 6.18 in regional contractors. For sub-contracted employees the numbers show a larger variation. This is probably due to the larger metro-based projects that require more sub-contractors and management staff.

The relatively large standard deviations (over 20 for the metropolitan firms) reflect the flexible, temporary organisations that are found in the modern construction industry. 
Figure 1: Size by average company turnover

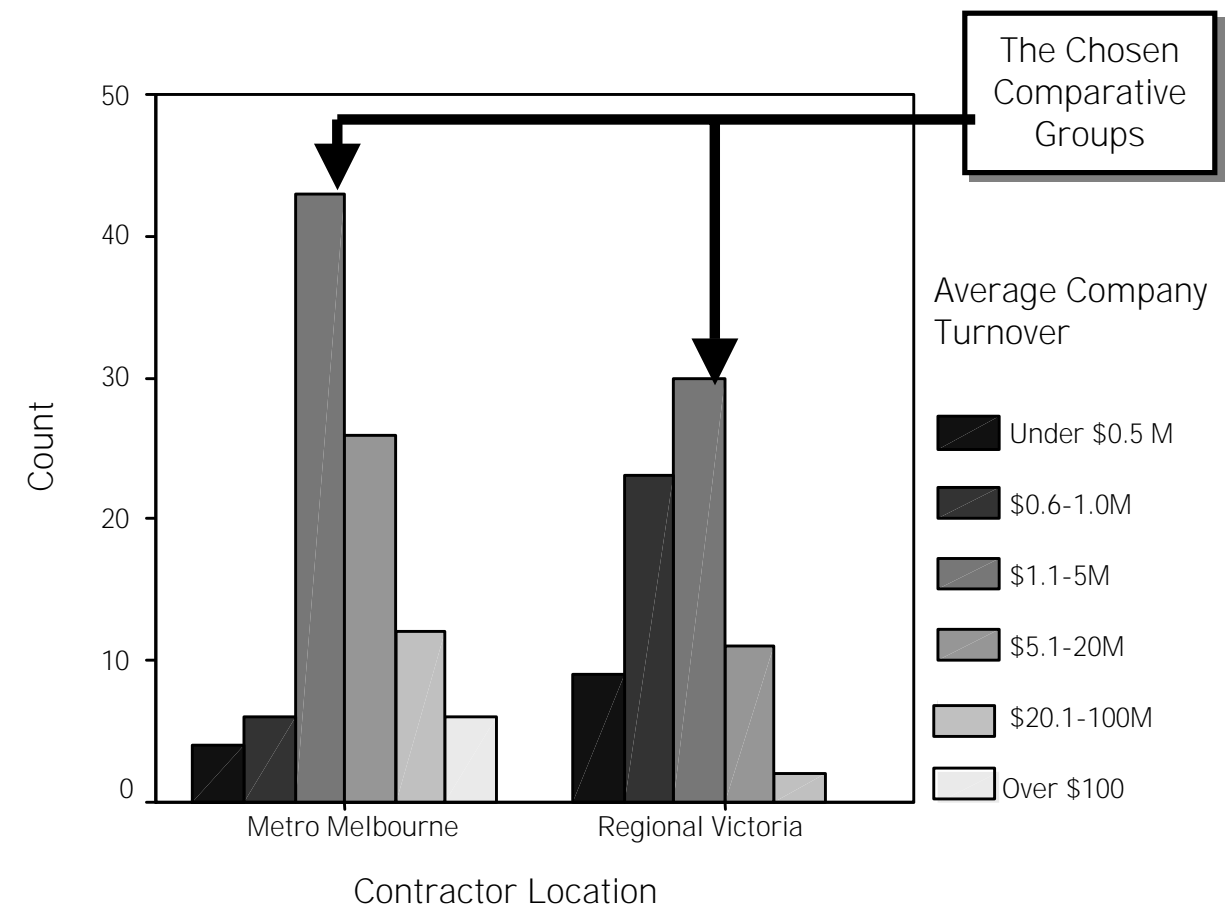

Table 1: Employee Numbers

\begin{tabular}{|l|l|l|l|l|}
\hline Contractor Location & \multicolumn{3}{|l|}{ Direct Empl oyee Numbers } & \multicolumn{2}{l|}{$\begin{array}{l}\text { Sub-Contracted Empl oyee } \\
\text { Numbers }\end{array}$} \\
\hline & Mean & Std Dev. & Mean & Std Dev. \\
\hline Metropolitan & 7.58 & 7.11 & 9.40 & 20.16 \\
\hline Regional & 6.18 & 3.54 & 5.27 & 7.09 \\
\hline
\end{tabular}

Table 2: Mean Likert Values for Operational Characteristics

\begin{tabular}{|l|l|l|l|l|l|l|}
\hline $\begin{array}{l}\text { Contractor } \\
\text { Location }\end{array}$ & $\begin{array}{l}\text { Working } \\
\text { Capital }\end{array}$ & $\begin{array}{l}\text { Credit for } \\
\text { Suppliers }\end{array}$ & $\begin{array}{l}\text { High } \\
\text { Interest } \\
\text { Rates }\end{array}$ & $\begin{array}{l}\text { Late } \\
\text { Payments }\end{array}$ & $\begin{array}{l}\text { PAYE to } \\
\text { PAYG }^{(a)}\end{array}$ & $\begin{array}{l}\text { GST } \\
\text { Admin } \\
\text { Burden }\end{array}$ \\
\hline Metropolitan & 2.21 & 1.46 & 2.40 & 3.16 & 2.51 & 3.49 \\
\hline Regional & 1.77 & 1.33 & 1.73 & 2.87 & 2.00 & 3.13 \\
\hline
\end{tabular}

(a) $\quad$ PAYE $=$ Pay As You Earn; PAYG $=$ Pay As You Go

(b) GST $=$ Goods and Services Tax

\section{Financial Operational Difficulties}

Six operational characteristics were compared and the average Likert $^{1}$ scale mean values are shown in Table 2 . In general the lower the Likert score the less respondents perceived the impact. In all cases the regional contractors experienced fewer problems in these operational areas as their average scores were lower under each heading. These interesting results undermine some assumptions often made about management in small to medium enterprises (SME's) in regional-based areas.

${ }^{1}$ Likert scale conversion: $1=$ not at all, $2=$ no guiding comment, $3=$ to some extent, $4=$ no guiding comment, $5=$ to a large extent. 
Table 4: Mean Likert values for Staff Devel opment/Learning

\begin{tabular}{|l|l|l|l|}
\hline Difficulty Experienced & Metropolitan & Regional & Total \\
\hline Internal Training & 2.20 & 2.40 & 2.28 \\
\hline Self Learning & 3.58 & 3.50 & 3.54 \\
\hline R \& D & 1.88 & 2.30 & 2.06 \\
\hline Company Benchmarking of Performance & 2.22 & 2.43 & 2.31 \\
\hline Project Reviews & 3.05 & 3.13 & 3.08 \\
\hline External Training Programs for staff & 2.83 & 2.50 & 2.69 \\
\hline Difficulty Obtaining Training for Site Workers & 1.83 & 2.33 & 2.04 \\
\hline Difficulty Obtaining Training for Managers & 1.95 & 2.21 & 2.06 \\
\hline Importance of Distance Traveled to training & 1.93 & 3.47 & 2.58 \\
\hline
\end{tabular}

Table 3: Mean Likert values for Labour Difficulties

\begin{tabular}{|l|l|l|l|l|l|}
\hline $\begin{array}{l}\text { Contractor } \\
\text { Location }\end{array}$ & Poor Morale & $\begin{array}{l}\text { Ineffective } \\
\text { Supervision }\end{array}$ & $\begin{array}{l}\text { Excessive } \\
\text { Stress }\end{array}$ & $\begin{array}{l}\text { Workforce } \\
\text { Conflict }\end{array}$ & Absenteeism \\
\hline Metropolitan & 1.90 & 2.00 & 2.18 & 1.79 & 1.71 \\
\hline Regional & 1.66 & 1.90 & 1.87 & 1.57 & 1.77 \\
\hline
\end{tabular}

\section{Labour Difficulties}

This section of the survey indicated similar results over the two groups. Again, except for the last characteristic, 'absenteeism', the regional builders' scores were lower than their metropolitan counterparts. The regional builders also perceive that there is less stress (1.87 compared with 2.18) in supervising and organising the labour in their jobs than those in metropolitan firms.

\section{Staff Development/Learning}

A significant difference is found between regional and metropolitan contractors in the issue of the importance of distance traveled to training facilities where the Likert scale average was 3.47 compared to 1.93 (Table 4). There is a important difference between these figures. This sentiment is consistent with the average response to internal training (higher) and their use of external training programs (lower) indicating a more independent approach to these issues.

Regional contractors also indicated they experienced more difficulties in getting training for site workers and managers when compared to the average response levels of metro-based contractors. $R e$ search and Development, Company Benchmarking and Project Reviews were perceived to be a bigger problem by regional contractors and this possibly points to their companies being more isolated from the body of knowledge and opportunities that the larger metropolitan (Melbourne) market has created. Table 4 summarises the nine characteristics measured under staff development and training.

It appears from these responses that regional builders are not using the regionally based technical and further education (TAFE) institutions to access training programs. Alternatively, these TAFE colleges are not providing the type of training programs and courses that regional builders want for staff in their businesses. The results from this section of the survey indicate a need to follow-up the reasons for these responses. Self Learning opportunities need to be urgently investigated as both groups indicated difficulties in this area (3.50 and 3.58).

In terms of the accessibility, respondents were also asked to indicate the average distance they travelled to training facilities. Naturally, regional contractors were involved in longer journeys with nearly $45 \%$ travelling an average round-trip distance of more than $100 \mathrm{~km}$. One regional firm was involved in travelling in excess of $500 \mathrm{kms}$ (round trip). The results are summarised in Table 5. Again, the role of regional TAFEs as vocational education must be explored to discover why this sector of the market appears to be travelling to the metropolitan area to gain suitable training programs. 
Table 5: Average distance travelled to training facilities

\begin{tabular}{|l|l|l|l|l|l|l|l|l|}
\hline \multicolumn{2}{|l|}{ Contractor Location } & $\begin{array}{l}1-15 \\
\mathrm{~km}\end{array}$ & $\begin{array}{l}16-50 \\
\mathrm{~km}\end{array}$ & $\begin{array}{l}51-100 \\
\mathrm{~km}\end{array}$ & $\begin{array}{l}101- \\
200 \mathrm{~km}\end{array}$ & $\begin{array}{l}201- \\
500 \mathrm{~km}\end{array}$ & $\begin{array}{l}> \\
500 \mathrm{~km}\end{array}$ & Total \\
\hline \multirow{2}{*}{ Metropolitan } & Count & 14 & 19 & 4 & 4 & - & - & 37 \\
\cline { 2 - 10 } & $\%$ & $37.8 \%$ & $51.4 \%$ & $10.8 \%$ & $10.8 \%$ & - & - & $100 \%$ \\
\hline \multirow{2}{*}{ Regional } & Count & 7 & 4 & 5 & 5 & 5 & 1 & 29 \\
\cline { 2 - 9 } & $\%$ & $24.1 \%$ & $13.8 \%$ & $17.2 \%$ & $24.1 \%$ & $17.2 \%$ & $3.4 \%$ & $100 \%$ \\
\hline
\end{tabular}

Table 6: Mean Likert values for market difficulties

\begin{tabular}{|l|l|l|l|}
\hline Difficulty Experienced & Metropolitan & Regional & Total \\
\hline Difficulty of Obtaining Sufficient Work in Area & 2.17 & 2.20 & 2.18 \\
\hline Excessive Competition for Work in Area & 2.60 & 3.13 & 2.82 \\
\hline $\begin{array}{l}\text { Difficulty Establishing Long Term Relationships with } \\
\text { Clients }\end{array}$ & 1.98 & 2.03 & 2.00 \\
\hline $\begin{array}{l}\text { Difficulty Obtaining Consistent Work of Most Preferred } \\
\text { Type }\end{array}$ & 2.48 & 2.53 & 2.50 \\
\hline Difficulty Obtaining Work of a Sufficiently Large Value & 2.49 & 2.53 & 2.51 \\
\hline Difficulty Obtaining Sub-Contractors in Structural Trades & 2.40 & 2.83 & 2.58 \\
\hline Difficulty Obtaining Sub-Contractors in Finishing Trades & 2.40 & 2.83 & 2.58 \\
\hline Difficulty Obtaining Sub-Contractors in Services Trades & 2.24 & 2.60 & 2.39 \\
\hline
\end{tabular}

Table 7: Distances travelled

\begin{tabular}{|l|l|l|}
\hline $\begin{array}{l}\text { Contractor } \\
\text { Location }\end{array}$ & $\begin{array}{l}\text { Average distance in } \mathrm{kms} \\
\text { travelled to site }\end{array}$ & $\begin{array}{l}\text { Average distance in kms materials are } \\
\text { sourced from and to site }\end{array}$ \\
\hline Metropolitan & 27.21 & 28.19 \\
\hline Regional & 55.60 & 86.25 \\
\hline
\end{tabular}

\section{Market Difficulties}

Of the eight variables surveyed, one of the biggest problems for both groups was $E x$ cessive Competition for Work in Area and the regional contractors felt this more keenly with an average score of 3.13. In fact, across all the variables, the regional contractors indicated that they had more difficulties in gaining work and competing than their metropolitan counterparts. The results shown in Table 6 are a reflection that the size of the regional market is smaller than the metropolitan market and that it experiences greater competition.

The fact that these contractors are in the largest size group (A $\$ 1.1$ - A $\$ 5.0$ million) naturally means there will be more competition from the greater number of builders. Further analysis of other size groups may provide an interesting comparison.

\section{Distances Travelled to Site}

Both groups noted that transportation costs of materials were not considered a major problem on most contracts. In fact, inspection and analysis of the Australian Construction Handbook (Rawlinsons, various editions) over the last twenty years shows a steady fall in locality allowances (mainly due to reducing transportation costs of materials). However, as could be expected the (higher) cost of fuel had a bigger impact on regional contractors $(30 \%)$ than the metropolitan group (12.2\%).

The mean distance travelled to sites was slightly more than double for the regional contractors at $55.6 \mathrm{~km}$ compared to 27.2 for the metropolitan contractors. The sourcing of materials showed a similar trend and these results are shown in Table 7.

\section{Information Technology}

The survey attempted to investigate the impact of information technology on builders and to identify and quantify the use of the Internet. The results are interesting and are summarised in Tables 8. 
Table 8: Connections to the Internet

\begin{tabular}{|l|l|l|l|l|}
\hline $\begin{array}{l}\text { Contractor } \\
\text { Location }\end{array}$ & No & Yes & Total \\
\hline Metropolitan & Count & 8 & 35 & 43 \\
\cline { 2 - 5 } & $\%$ & $18.6 \%$ & $81.4 \%$ & $100 \%$ \\
\hline \multirow{2}{*}{ Regional } & Count & 4 & 26 & 30 \\
\cline { 2 - 5 } & $\%$ & $13.3 \%$ & $86.7 \%$ & $100 \%$ \\
\hline
\end{tabular}

The surprising figure of $86.7 \%$ of Internet connections for the regional contractors exceeded that of the metropolitan group of $81.4 \%$. The regional builders are connected and it would be now useful to discover whether the full potential of the Internet is being realised. The next stage of the research will identify whether e-business and other capabilities can be integrated into the regional builders' businesses - that is, can the high level of internet connection be usefully exploited?

\section{CONCLUSIONS}

All Australian state governments have expressed a desire to maintain the viability of their regional economies. It is in the interests of the regional communities themselves that this essential part of the cultural, social and economic fabric of national life is given renewed vigor (Storper, 1997). It is important that regional construction economy is not ignored in the Government's national quest to improve the economic performance of the construction industry.

Regional building and construction companies have much to gain from linking into expanded networks of IT and e-commerce. The impressive Internet connection of regional contractors (86.7\%) indicates that a strategy of upgrading and increasing awareness of IT has a sound basis for a number of e-commerce and training developments. Regional building companies must be given the opportunity to participate in the strategy specified in the Federal Government's Action Agenda (DISR, 1999), by:

- fostering the use of alliancing between metropolitan and regional based contractors

- increasing awareness of the benefits of IT

- supporting the development of industry standards and shared databases

- encouraging and focusing on added value from the use of IT
- supporting restructuring of the industry supply chain to leverage benefits from IT.

This research indicates that such policies may succeed with suitable support in some key areas. If the regional tendering situation is not addressed, metropolitan-based building contractors will continue to win the medium to large construction projects in regional areas ahead of the local competition. This has the effect of further reducing the capacity of regional-based builders who cannot grow to add to the competitive environment that creates an innovative and efficient construction industry.

The problems in regional Australia are probably common to many countries. These problems, opportunities and initiatives found in construction firms in regional areas around the world need to be shared to find solutions to the common problems, especially when better communications can bring the regions closer to the dominant metropolitan areas.

\section{REFERENCES}

ABS (1999) Private Sector Construction Industry, Australian Bureau of Statistics, Commonwealth of Australia.

Briscoe, G. (1988) The economics of the construction industry. Mitchell Press.

Chan, A. P. C. and Fung, C. Y. (1996) Procurement systems in Australia. Proceeding of CIB W-89, 21-24 October. Beijing, China.

Disney, J . (1993) Regional Development and Australia's future, Australian Council of Social Services, Office of Local Government.

DISR (1999) Building for growth: The building and construction action agenda, Department of Industry Science and Resources, Commonwealth of Australia.

Drew, D. and Skitmore, R. M. (1997) The effect of contract type and size on competitiveness in bidding. Construction Management and Economics 15, 469-489. 
Langford, D. and Male, S. (1991) Strategic management in construction: conceptual foundations. Heinemann.

Rawlinson (1994) Rawlinson's Australian Construction Handbook 1994, 12 edn. Rawhouse Publishing Pty Ltd.

Runeson, G. (2000) Building Economics. Deakin University Press.

Smith, J., Love, P. and J ackson, N. (2000) Regional tendering Markets: Improving the capability of regional tenderers, Deakin University, Prepared for the Department of Infrastructure, Building Policy, Government of Victoria., 36.

Steinke, J. C. (1977. Australian Regional Policy and Regional Population Trends 1947-1971, Department of Decentralisation and Development, NSW.

Storper, M. (1997) The regional world: Territorial development in a global economy. Guildford Press. 